\title{
Accumulation of polyphenols and flavonoids in Atriplex canescens (Pursh) Nutt stressed by heavy metals (zinc, lead and cadmium)
}

\author{
Khedim Ikram a, ${ }^{*}$, Reguieg Yssaad Houcine Abdelhakim a, Bülent Topcuoglu b, Osmane Badiaa ${ }^{a}$, \\ Tadjouri Houria ${ }^{\text {a }}$. \\ a Laboratory of biodiversity and conservation of water and soils, Faculty of Nature and Life Sciences, University of Abdelhamid Ibn Badis, \\ Mostaganem, Algeria \\ ${ }^{b}$ Department of plant and animal, Akdeniz University Vocational School of Technical Sciences, Antalya, Turkey
}

*Corresponding Author: messalitieps@hotmail.fr

Article history

Received 18 February 2019

Revised 17 April 2019

Accepted 31 January 2020

Published Online 15 June 2020

\begin{abstract}
Pollution of the environment and soils by heavy metals is one of the major problems of our time. Our study was to determine the effect of five doses for : zinc, lead and cadmium $(0,2500,5000,7500$, and $10000 \mathrm{ppm}$ ) applied to the Atriplex canescens after 60 days for two weeks. The results showed an increase in the total polyphenols and flavonoids, depending on the increasing concentration of heavy metals at the leaf and root levels. The leaves have total polyphenols and flavonoids higher than those of the roots. The highest levels of total polyphenols and flavonoids in the leaves $(3.47 \mathrm{mg}$ EAG/ gdry weight of total polyphenols and $3.70 \mathrm{mg} \mathrm{EQ} / \mathrm{g}$ dry weight of flavonoids) were obtained at a dose of $10000 \mathrm{ppm}$ (cadmium, lead) respectively. On the other hand, the highest levels of total polyphenols and flavonoids in the roots were obtained at the metallic dose of $10000 \mathrm{ppm}$ for cadmium (3.38 mg EAG/ g dry weight of total polyphenols and $0.61 \mathrm{mg} \mathrm{EQ} / \mathrm{g}$ dry weight of flavonoids). These results also underlined the important role of secondary metabolites (total polyphenols and flavonoids) in the defense against oxidative stress caused by metallic stress.
\end{abstract}

Keywords: Heavy metals, Atriplex canescens (Pursh) Nutt, total polyphenols, flavonoids.

\section{INTRODUCTION}

The increasingly growing of human agricultural, urban and industrial activities has caused the contamination of our environment by heavy metals. Heavy metals are not able to degrade and their concentration increases steadily in soils. This exposes plants to increasing concentrations of heavy metals. Phytoremediation is one of the biological methods based on the use of plants to eliminate or degrade heavy metals in contaminated soil [1]. In response to various environmental stresses, plants have storage or detoxification systems that allow them to reduce the harmful effects of heavy metals [2]. One of the main traits of tolerance to environmental stresses is the synthesis of the secondary metabolite such as total polyphenols and flavonoids, which plays a crucial role in the detoxification of reactive oxygen species [3]. The effectiveness of these substances to stop the free radical reactions by neutralizing free radicals is mainly due to their phenolic structures with the presence of the hydroxyl groups [3].

Several species belong to the genus Atriplex are well adapted to harsh environmental conditions and characterized by their great diversity with more than 400 species [4]. It is a useful material for the identification of physiological mechanisms involved in resistance to abiotic stresses [5]. Atriplex canescens (Pursh) Nutt is a halophyte being a part of the family of chenopodiaceae, come from North America [6].

In this context, our work was designed to evaluate the effect of heavy metals zinc, lead and cadmium on the contents of total polyphenols and flavonoids of Atriplex canescens (Pursh) Nutt.

\section{EXPERIMENTAL}

\section{Materials}

\section{Plant material}

The plant material that was the subject of this study involved only the seeds of the Atriplex canescens (Pursh) Nutt of the chénopodiacée family. The seeds of the Atriplex canescens originated in the $\mathrm{El}$ Bayedh region and were collected in December (2015).

\section{Seed Preparation}

The seeds were manually peeled, disinfected with bleach for 5 minutes and then rinsed abundantly with distilled water to remove all traces of chlorine. Lastly they were dried before germination.

\section{Germination}

Seeds were sown in alveoli to obtain seedlings. Each cell contained a seed. These seeds were irrigated with distilled water once every two days.

\section{Transplant}

After one month of germination, seedlings were transplanted into cylinders (height $50 \mathrm{~cm}$ and diameter $20 \mathrm{~cm}$ ) that bottom lined with a 
layer of gravel to ensure drainage and filled with a sand/potting mixture $(2 \mathrm{~V} / \mathrm{V})$.

\section{Watering}

Watering was carried out three times a week by distilled waters and substituted once in three by a nutrient solution of [7] until a sufficient plant material was obtained for the analyses.

\section{Application of stress}

Metal stress was applied to the plant after 60 days for two weeks. Five metal doses $(0,2500,5000,7500$, and $10000 \mathrm{ppm})$ were selected for $\mathrm{Zn}, \mathrm{Pb}$, and $\mathrm{Cd}$ Metals.

\section{Collection and preparation of plant material for analysis}

After two weeks of the stress, plants were removed for obtaining leaves and roots that were dried at $80{ }^{\circ} \mathrm{c}$ for $24 \mathrm{~h}$.

\section{The parameters analyzed}

\section{Total polyphenol Content}

The total polyphenol content was determined by the folicCicalteu reagent method [8] by measuring the absorbance at $760 \mathrm{~nm}$.

\section{Flavonoid content}

The flavonoid content was determined by the aluminum trichloride method [9]. The contents were expressed in $(\mathrm{mg} \mathrm{EQ} / \mathrm{g})$ dry weight after reading the D.O at $430 \mathrm{~nm}$ on a spectrophotometer JENWAY 6505UV/Vis.

\section{Statistical analyzes}

The results obtained were treated statistically using the STATBOX software. Version 6.4 , an analysis of the variance calling to the test of Newman-Keuls $\mathrm{P}=5 \%$.

\section{RESULTS}

\section{Total Polyphenols}

Total polyphenols content of the leaves and roots of Atriplex canescens stressed to zinc

The content of total polyphenols in the aerial and root parts of Atriplex canescens was increased with increasing of zinc concentration (Fig. 1).

For the same concentrations of zinc, accumulation of total polyphenols in the leaves was higher than that recorded in the roots of the plant. The total polyphenols were spread out evenly in the leaves $3.22,3.29,3.30$ and $3.31 \mathrm{mg}$ EAG / g weight dry of total polyphenols stressful doses 2500, 5000, 7500 and $10000 \mathrm{ppm}$ of zinc, respectively.

The application of zinc caused an increase of polyphenols levels in the roots at 2500, 5000, 7500 and $10000 \mathrm{ppm}(3.09,3.22,3.30$ and $3.30 \mathrm{mg}$ EAG / g dry weight of total polyphenols, respectively) compared with the control (2.90 mg EAG / g dry weight of total polyphenols).

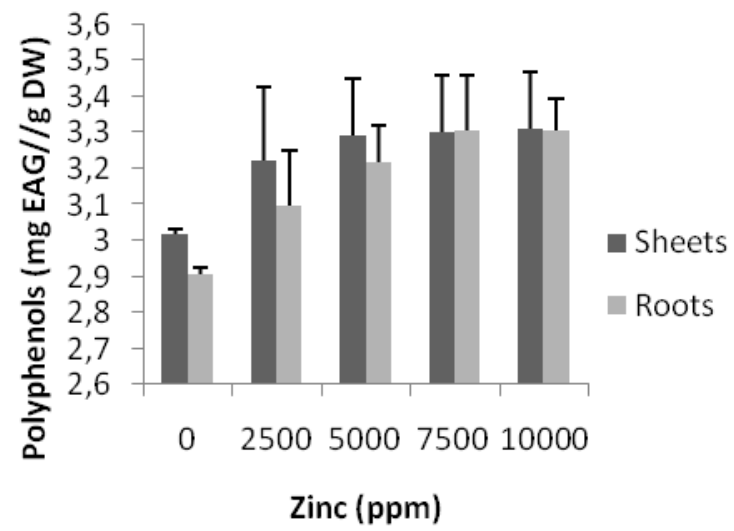

Fig. 1 Polyphenols content total (mg EAG / g dry weight) of the leaves and roots of Atriplex canescens (Pursh) Nutt stressed to zinc.
Statistical analysis using the Newman-Keuls test at $\mathrm{P}=5 \%$ showed insignificant effect of zinc treatment on the accumulation of total polyphenols in the stressed leaves compared with the control leaves. Thus, the values of the total polyphenols content under all treatments were significantly varied $(\mathrm{P}=0.00)$ for the roots.

\section{Total polyphenols content of the leaves and roots of Atriplex} canescens stressed to lead

The results found in the stressed plants led to different concentrations $(2500,5000,7500$ and $10000 \mathrm{ppm})$ and revealed an increase of total polyphenols in the leaves and roots of Atriplex canescens (Fig. 2). The contents obtained in total polyphenols were elevated in the leaves of the plant $(3.23,3.28,3.31$ and $3.34 \mathrm{mg}$ EAG / $\mathrm{g}$ dry weight of total polyphenols) than the roots $(3.18,3.18,3.30$ and $3.32 \mathrm{mg}$ EAG / g dry weight of total polyphenols).

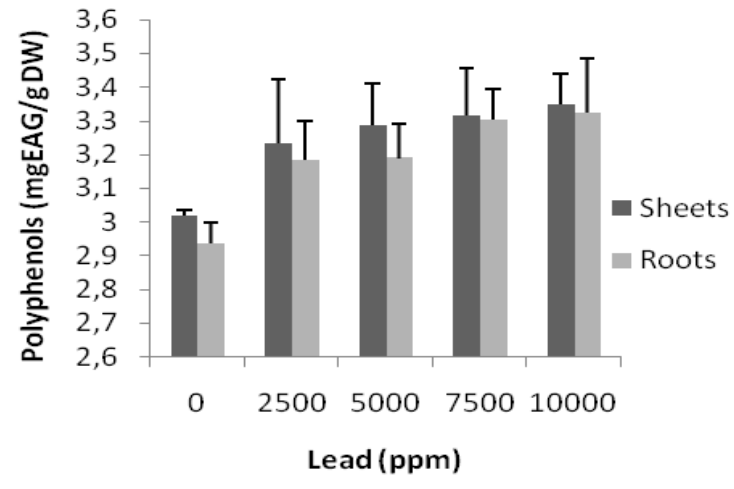

Fig. 2 Polyphenols content total (mg EAG / g dry weight) of the leaves and roots of Atriplex canescens (Pursh) Nutt stressed to lead.

Statistical analysis using the Newman-Keuls test at $\mathrm{p}=5 \%$ revealed that the total polyphenol levels were significantly accumulated in the leaves and roots of the Atriplex canescens $(\mathrm{P}=$ $0.00)$ relative to the leaves and roots of the plants witnesses.

\section{Total polyphenols content of the leaves and roots of Atriplex} canescens stressed to cadmium

The results showed that the accumulation of total polyphenols was higher in the leaves than in the roots of the plant Atriplex canescens. The accumulation of total polyphenols in the leaves and roots of the plant was increased progressively with increasing doses of cadmium (Fig. 3).

In the leaves, the highest total polyphenols content (3.47 mg EAG /g dry weight of total polyphenols) was obtained for treatment at $10000 \mathrm{ppm}$ of cadmium while the total polyphenol content (3.25, 3.30 and $3.42 \mathrm{mg}$ EAG / g dry weight of total polyphenols) was obtained for treatments at 2500, 5000 and $7500 \mathrm{ppm}$ of cadmium, respectively.

In the roots, the highest total polyphenols content (3.38 mg EAG/ $\mathrm{g}$ dry weight) was obtained for treatment at $10000 \mathrm{ppm}$ of cadmium.

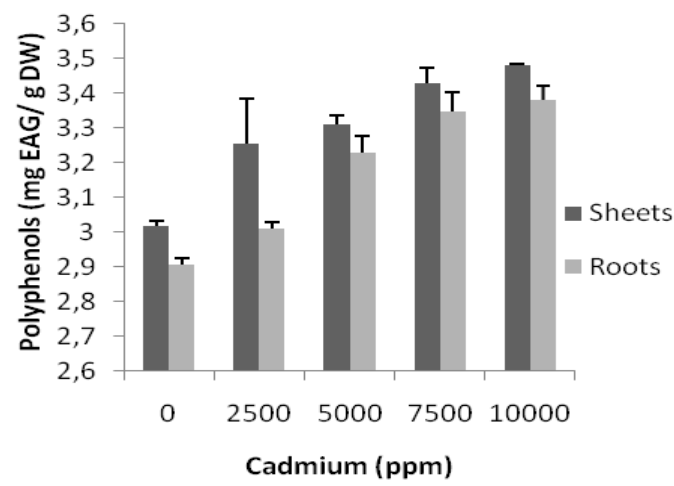

Fig. 3 Polyphenols content total (mg EAG / g dry weight) of the leaves and roots of Atriplex canescens (Pursh) Nutt stressed to cadmium. 
The analysis of the variance revealed a very highly significant difference in the leaves and roots of the plants stressed in relation to the leaves and roots of the control plants.

\section{Flavonoids}

Flavonoid content of the leaves and roots of Atriplex canescens stressed to zinc

The results showed an increase in the flavonoid content in the leaves and roots in the plant Atriplex canescens.

In the leaves, there was a significant increase in the flavonoids of plants subjected to stress by zinc compared to the control, because in the leaves of plants subjected to $7500 \mathrm{ppm}$ flavonoid content decreases slightly (Fig. 4).

The application of zinc resulted in a decreased content of flavonoids in the roots at 2500, 5000 and $7500 \mathrm{ppm}(0.33,0.43$ and $0.46 \mathrm{mg}$ EQ / g dry weight of flavonoids) successively relative to the control (0.53 mg EQ / $\mathrm{g}$ weight dry of flavonoids). While in the roots of the plants subjected to $10000 \mathrm{ppm}$ of zinc, flavonoid content was increased slightly compared to the control.

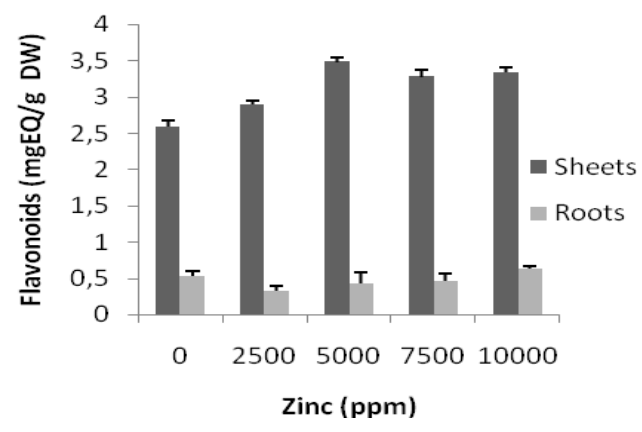

Fig. 4 Content of flavonoids (mg EQ / g dry weight) of the leaves and roots of Atriplex canescens (Pursh) Nutt stressed to zinc.

The statistical analysis indicated that the zinc effect on the accumulation of flavonoids was highly significant in the leaves and roots of the plants Atriplex canescens.

\section{Flavonoid content of the leaves and roots of Atriplex canescens stressed to lead}

The level of flavonoids in the leaves and roots of Atriplex canescens was increased progressively with increasing doses of lead applied to the plant. The flavonoid content was greater in the leaves than in the roots of the plant (Fig. 5).

In the leaves, the higher content of flavonoids (3.70 mg EQ / g dry weight of flavonoid) was obtained for the treatment of 10000 $\mathrm{ppm}$ of lead. A slight decrease was noted for flavonoid stressful dose of $2500 \mathrm{ppm}$ of lead (2.57 mg EQ / g dry weight of flavonoid) compared to control (2.58 mg EQ / g dry weight of flavonoid).

In contrast, in the roots of the plant Atriplex canescens, flavonoids were accumulated very slowly when the lead concentration was increased.

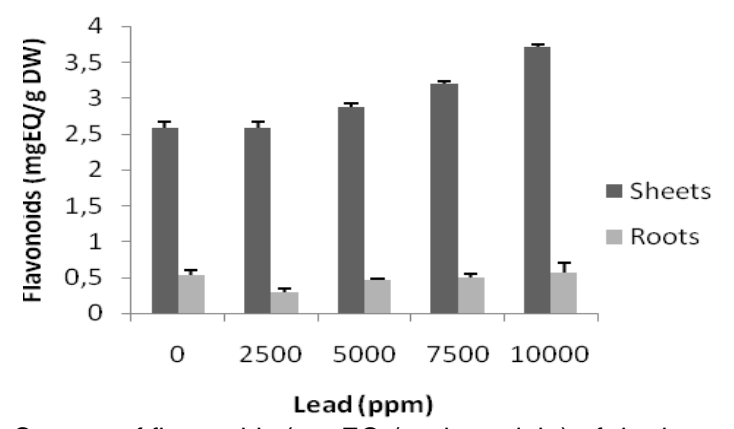

Fig. 5: Content of flavonoids (mg EQ / g dry weight) of the leaves and roots of Atriplex canescens (Pursh) Nutt stressed to lead.

Statistical analysis indicated that flavonoids were accumulated in a highly significant way in leaves and roots with all lead treatments.

\section{Flavonoid content of the leaves and roots of Atriplex canescens stressed to cadmium}

The results showed that the applied cadmium caused an increase in flavonoid levels in the leaves of the plant 2500, 5000, 7500 and $10000 \mathrm{ppm}(2.72,3.30,3.51$ and $3.39 \mathrm{mg}$ EQ / g dry weight of flavonoids respectively) compared to control (2.58 mg EQ / g dry weight of flavonoids), which was against by the roots, the accumulation of flavonoids was decreased progressively with increasing doses of cadmium. While in the roots of the plants subjected to $10000 \mathrm{ppm}$ of cadmium, flavonoid content was increased slightly compared to the control (Fig. 6).

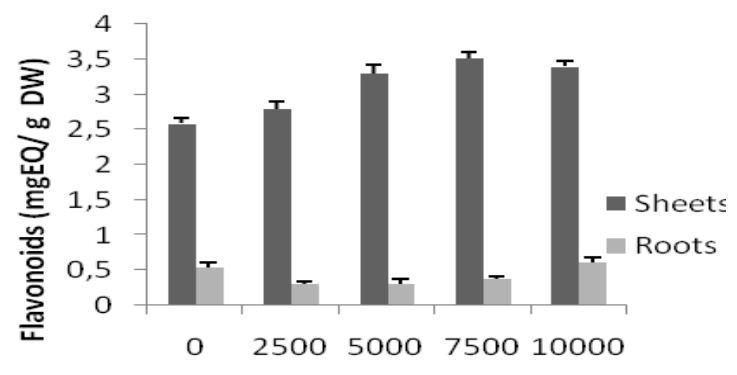

Cadmium (ppm)

Fig. 6: Content of flavonoids (mg EQ / g dry weight) of the leaves and roots of Atriplex canescens (Pursh) Nutt stressed to cadmium.

The statistical study highlighted a highly significant response to the effect of cadmium on the accumulation of flavonoids in leaves and roots by contribution to the control plants of the Atriplex canescens.

\section{DISCUSSION}

The main obtained results showed that:

The levels of polyphenols were elevated at the level of the leaves and roots of the Atriplex canescens under metallic stress compared to the control plant. These results were consistent with those of [10] or observed an increase in polyphenols under the effect of metallic stress in Vicia faba L. Phenolic compounds intervene in many mechanisms to allow the plant to adapt to its medium [11].

Polyphenols are capable of preventing membrane lipid peroxidation and capturing hydroxyl, superoxide and peroxyl radicals $[12,13]$.

The large accumulation of polyphenols in the stressed plant with heavy metals (zinc, cadmium and lead) was a response to metallic stress unlike the unstressed plant or the rate of polyphenols was low, because according to [11], the accumulation of polyphenols could play an essential role in the balance and adaptation of the plant. Polyphenols are capable of acting as antioxidants that can trap free radicals, resulting in the suppression of the formation of ERO by inhibition of some enzymes or by chelation of the metal ions, involved in their production, and the protection of antioxidant defense systems of the organism [14].

Indeed, polyphenols possessed hydroxyphénolic groups in their structures and the antioxidant properties were attributed in part, to the ability of these natural compounds to trap free radicals such as hydroxyl radicals $\left(\mathrm{OH}^{\circ}\right)$ and Superoxides $\left(\mathrm{O}_{2}{ }^{\circ}\right)[15]$.

This accumulation was more important in the leaves than in the roots, in this regard several authors $[16,17,18]$ showed the richness of the leaves of cereals in polyphenols which possessed with great antioxidant power.

The accumulation of phenolic compounds, especially flavonoids, has been demonstrated in many species and in different situations of biotic stress [19], also under abiotic conditions [20].

The flavonoid content in the leaves and roots in the Atriplex canescens was increased proportionately with the concentration of heavy metals, because according to [21], flavonoids are found in large quantities in the different parts of the Plant under the influence of different stresses. 
For the concentrations of 2500,5000 and 7500 of (zinc, lead and cadmium), a decrease in the rate of flavonoids was observed at the root parts level, this could be explained by the resistance of the plants to these concentrations. The response of plants to metal stresses varies from one concentration to another. The results obtained on the significant accumulation of the flavonoid in the stressed plant were corroborated with those of [22] that bound the accumulated amounts of flavonoids to stress tolerance. Consistent with a study done by [23] showing those flavonoids as good chelators of heavy metals.

Indeed, phenolic compounds and especially flavonoids are recognized as potentially antioxidant substances with the ability to trap radical species and reactive forms of oxygen. These compounds participate very effectively in the tolerance of plants to various stresses [11].

\section{CONCLUSION}

The response of Atriplex canescens to metal stress has resulted in an increase in antioxidants (polyphenols, flavonoids) as a function of the increasing concentration of heavy metals, this increase was more important in the leaves than roots.

Accumulation of total polyphenols and flavonoids was very important in stressed Atriplex compared with the unstressed plant.

According to the results obtained it could be concluded that the plant Atriplex canescens could be exploited for use for the decontamination of the soils by the approaches of the phytoremediation.

\section{ACKNOWLEDGEMENT}

We would like to initially thank God for giving courage and the will to complete this work. We also would like to thank to anonymous references for their suggestions which significantly improved the manuscript.

\section{REFERENCES}

[1] Sutherzann, S. 2001. Natural and Enhanced Remediation Systems. CRC Press, p440.

[2] Remon, E. 2006. Tolérance et Accumulation Des Métaux Lourds Par La Végétation Spontanée Des Friches Métallurgiques : Vers de nouvelles Méthodes De Bio-Dépollution. Thèse de doctorat de l'Université de Jean Monnet., pp 157.

[3] Nijveldt, R. J., E. Nood, D. E. Hoorn, P.G. Boelens, K. Norren, P. Leeuwen. 2001. Flavonoids: A review of probable mechanisms of action and potential applications. The American Journal of Clinical Nutrition, 74(4) : 418-425.

[4] Le Houérou, H. N. 1992. The role of salt bushes (Atriplex spp) in arid lands rehabilitation in the Mediterranean basin. A review. Agroforestry systems, $18: 107-148$.

[5] Wang, L. W., A. M. Showalter. 2004. Cloning and salt-induced, ABA independent expression of choline mono-oxygenage in Atriplex prostrata. Physiologia Plantarum, 120 : 405-412.

[6] Mulas, M., G. Mulas. 2004. The potential for strategic use of plants of the genera Atriplex and Opuntia in the fight against desertification. Short and Medium - Term Priority Environmental Action Program. University of Studies of Sassari Research Group on Desertification., pp 112.

[7] Hoagland, D. R., D. I. Arnon. 1938. The water-culture method for growing plants without soil. Circular. California Agricultural Experiment Station, 347: 1-39.

[8] Singleton, V. L., J. A. Rossi. 1965. Colorimetry of total phenolics with phosphomolybdic- phosphotungstic acid reagents. American Journal of Enology and Viticulture., $16: 144-158$.

[9] Bahorun, T., B. Gressier, F. Trotin, C. Brunete, T. Dine, J. Vasseur, J. C. Gazin, M. Pinkas, M. Luycky, M. Gazin. 1996. Oxygen species scavenging activity of phenolic extracts from hawthorn fresh plant organs and pharmaceutical preparations. Arzneimittel-Forschung., 46 :1086-1089.

[10] Sgherri, C., M.F. Quartacci and F. Navari-Izzo. 2007. Early production of activated oxygen species in root apoplast of wheat following copper excess. Journal of Plant Physiology., 164(9) :1152-1160.

[11] Macheix, J. J., A. Fleuriet, C. Jay-Allemand. 2005. Les composés phénoliques des végétaux: Un exemple de métabolites secondaires d'importance économique. Ed. Presses polytechniques et universitaires romandes, Lausanne., pp 4-5.

[12] Anderson, C. M., A. Hallberg, T. Hogberg. 1996. Advances in the développement of pharmaceutical antioxidant drug. Food Chemistry, 28 : 65-180.

[13] Hu, Z. Z., M. Narayanaswamy, K. E. Ravikumar, K. Vijay-Shanker, C. H. Wu. 2005. Literature mining and database annotation of protein phosphorylation using a rule-based System., pp 2759-2765.

[14] Boudiaf, K. 2006. Etude des effets anti-xanthine oxydoreductase et anti -radicalaires des extraits des graines de Nigellasativa. Mémoire de magister -Université de Sétif.

[15] Bartosz, G. 2003. Génération of reactive oxygen species in biological Systems. Comments on Toxicology, 9: 5-21.

[16] Abdel-Aal, E. S. M., J. C. Young, I. Rabalski. 2006. Anthocyanin composition in black, blue, pink, and red cereal grains. Journal of Agricultural and Food Chemistry, 544-696.

[17] Jonnala, R. S. 2010. Phenolics in the bran of waxy wheat and triticale.

[18] Chaib, G. H., A. Bouchelaleg, R. Talbi. 2015. Etude phytochimique de quelques variétés de blé tendre (Triticumaestivum) et d'orge (Hordeumvulgare) et leurs activités biologiques. European Scientific Journal., 11(30): 1857 - 7881

[19] War, A. R, M. G. Paulraj, M. Y. War, S. Ignacimuthu. 2011. Differential defensive response of groundnut to Helicoverpaarmigera (Hubner) (Lepidoptera: Noctuidae). Acta Physiologiae Plantarum, 34 : 343-352.

[20] Korkmaz, A., M. Zuzunlu, A. R. Demirkiran. 2007. Treatment with acetyl salicylic acid protects muskmelon seedlings against drought stress. Franciszedgorski institute of plant physiologie. Polish academy of Science. Krakaow, tyrkey.

[21] Smirnoff, N. 2005. Antioxidants and reactive oxygen species in plants. Oxford Blackwell Publishing., pp 53-86.

[22] Walton, N. J., D. E. Brown 1999. Chemivals from plants, Perspectives on secondary products, World Scientific., pp 56-66.

[23] Morris, C. J., J. R. Earl, C. W. Trenam, D. R. Blake. 1995. Reactive oxygen species and iron a dangerous partnership in inflammation. The International Journal of Biochemistry \& Cell Biology, 27: 109-122. 